\title{
o CHC e seus desafios
}

\section{Shozo Motoyama}

Aconteceu há 15 anos atrás, em 1988. Criava-se o Centro Interunidade de História da $\mathrm{Ci}$ ncia e da Tecnologia (CHC/USP), na Universidade de $\mathrm{S}$ o Paulo. $\mathrm{O}$ ent o reitor José Goldemberg assinou a Resoluç o 3.457/88, tornando em realidade uma antiga reivindicaç o de docentes e pesquisadores interessados em aprofundar o conhecimento da ci ncia e tecnologia ( $\mathrm{C} \& \mathrm{~T})$ na sua dimens o histórica, filosófica, metodológica, sociológica e pol tica. Imersos no clima da globalizaç o que começava a acentuar-se na época, esses professores viam com preocupaç o a banalizaç o da investigaç o cient fica e tecnológica, a cientometria puramente quantitativa, a depend ncia aos modelos estrangeiros. Isso porque, a globalizaç o, ao contrário do que o seu nome sugere, exige cada vez mais compet ncia nacional - para servir de moeda de troca no cenário internacional -, principalmente no dom nio da $\mathrm{C} \& \mathrm{~T}$, o motor desse processo.

Assim, para a realizaç o de pesquisas, social e culturalmente significativas, $\mathrm{n}$ o basta apenas publicar em revistas internacionais, completando, aqui e acolá, teses já desenvolvidas alhures. $\mathrm{N}$ o é que esse tipo de trabalho, n o tenha o seu valor. Mas, por certo, n o satisfaz, nem as mentes mais inquiridoras, nem a sociedade brasileira que o financia. Para esta, interessa a investigaç o imbricada com a sua realidade social e econ mica ou, ent o, uma de cunho fortemente original, suficiente para 
enfrentar a concorr ncia econ mica e/ou intelectual. Entretanto, tais resultados $\mathrm{n}$ o se conseguem apenas com expedientes comuns nos corredores universitários, de t o somente ensinar técnicas e táticas de pesquisa, ao lado de fornecer dados e informaç es. Embora, necessários, eles n o s o suficientes. É preciso, também, pensar no aspecto estratégico da C\&T, intimamente correlacionado com as dimens es apontadas acima. Para se movimentar com efici ncia no cipoal de variáveis concernentes ao processo histórico, essa vis o estratégica alicerçada na história é fundamental. Dessa forma, o $\mathrm{CHC}$, ainda que modestamente, vinha para ajudar a preencher essa lacuna.

Entretanto, o interesse pela história da ci ncia e tecnologia na USP, já vinha de longa data. Alguns pioneiros, visionários de larga vis o, ventilaram ao longo dos anos a import ncia de se desenvolver investigaç es históricas da C\&T, seja com finalidades educativas, seja com objetivos culturais. Talvez, um exemplo t pico tenha sido o professor Heinrich Rheinboldt, qu mico alem o, encarregado de dirigir, a partir de 1935, a ent o iniciante Seç o de Qu mica, da Faculdade de Filosofia, Ci ncia e Letras (FFCL), fundada no ano anterior. Pesquisador competente e docente exemplar, Rheinboldt formou um grupo qualificado de qu micos uspianos, uma verdadeira escola. Ao lado dessa atividade, ele realizou uma outra menos conhecida, mas, nem por isso menos importante - a investigaç o na área de história da qu mica. Um dos editores da revista Chymia, o mais conhecido periódico internacional especializado dessa área, Rheinboldt tinha um lugar ao sol entre os historiadores da qu mica. Transmitiu o seu entusiasmo sobre essa disciplina aos seus disc pulos brasileiros, sobretudo, apontando o valor pedagógico e cultural de estudos históricos da ci ncia. Um dos seus melhores trabalhos nesse campo diz respeito história da qu mica no Brasil. Todavia, ele n o era o único na USP. Estava bem acompanhado por pesquisadores e professores do calibre de Fernando de Azevedo, Abrah o de Moraes, Victor Leinz, Mário Guimar es Ferri, Benedito Castrucci e outros.

Contudo, a institucionalizaç o da disciplina vai se dar somente no in cio doa anos 60 do século XX. Adiantando-se s outras universidades brasileiras, no Departamento de F sica da USP, oficializou-se a criaç o de uma disciplina de História das Ci ncias, sob a inspiraç o de Mário Schenberg. Entrementes, a F sica n o estava sozinha. Em outros departamentos, igualmente, ocorriam aç es tentando viabilizar a disciplina ou 
ent o introduzir uma correlata, a filosofia da ci ncia. $\mathrm{Na} \mathrm{Qu}$ mica, Sim o Mathias esforçava-se em concretizar o ensino da história dessa matéria. $\mathrm{Na}$ Biologia, Ant nio Brito da Cunha estimulava o ensino da filosofia da ci ncia. Esta era ensinada na Escola Politécnica, graças ao empenho de Milton Vargas e Nilo do Amaral. Esses acontecimentos relacionavam-se com as caracter sticas pessoais dos professores citados, mas refletiam, de igual maneira, a tend ncia internacional, vis vel após a Segunda Guerra Mundial, da valorizaç o da história e filosofia da ci ncia, principalmente nos Estados Unidos.

Em 1970, Eur pedes Sim es de Paula, ent o diretor da Faculdade de Filosofia, Letras e Ci ncias Humanas (FFLCH), deu o passo seguinte para reforçar a institucionalizaç o do campo. No ano anterior, ocorrera uma reforma universitária imposta pelo regime militar, na qual os departamentos cient ficos da antiga FFCL tornaram-se em unidades independentes. Eur pedes, olhava com preocupaç o esse desmembramento que poderia agravar o valo existente entre as duas culturas - a das humanidades e a das ci ncias - no bom estilo do Sir Charles Snow. Percebendo em história da ci ncia um elo capaz de minorar essa separaç o danosa, ele resolveu implantar no Departamento de História da sua faculdade, essa disciplina. Para a sua sorte, alguns professores interessados nessa matéria tinham sidos remanejados para esse departamento pela reforma mencionada acima. Da F sica vieram Junichi Osada, Maria Amélia M. Dantes e Shozo Motoyama, e das Ci ncias Farmacéuticas, o professor Carlos $\mathrm{H}$. Liberalli.

Porém, logo de in cio, o grupo teve duas baixas. Lamentavelmente, o professor Liberalli que vinha desenvolvendo estudos de grande interesse sobre a obra cient fica de José Bonifácio de Andrada e Silva, faleceu vitimado de c ncer. Por outro lado, o professor Junichi Osada resolveu transferir-se para o recém criado Instituto de $\mathrm{F}$ sica. Os dois restantes eram jovens na época e com pouca experi ncia. Nesse sentido, o apoio do professor Sim es de Paula foi decisivo para a sobreviv ncia da disciplina. Com o doutoramento da Maria Amélia M. Dantes, em 1973 e de S. Motoyama, dois anos antes, em 1971, seguido de estágios no exterior de ambos, o grupo ganhou mais consist ncia e capacitaç o. Também, a transfer ncia de Sim o Mathias - qu mico bem conhecido - para o Departamento de História, em 1973, aumentou ainda mais a potencialidade desse núcleo. Em torno desses tr s docentes, formou-se um conjunto in- 
formal de jovens pesquisadores e estudantes preocupados em indagar o significado social e a natureza da ci ncia. Essas preocupaç es vinham de encontro, como uma cr tica, ao clima instável e de terror, estabelecido pelo malfadado Ato Institucional N. ${ }^{\circ} 5$ promulgado pelo regime militar vigente, responsável pela cassaç o arbitrária de algumas das nossas melhores intelig ncias.

No entanto, é preciso que se diga, na primeira metade dos anos setenta, o campo ganhou mais visibilidade em funç o da atividade de alguns pesquisadores de grande gabarito, mas n o especializados em história da ci ncia. S o os casos de José Goldemberg, de Maur cio O. da Rocha e Silva, de Ant nio de B. Ulh a Cintra, de Erasmo Garcia Mendes, de Ricardo de C. Ferreira, de Francisco Romeu Landi, de Nestor Goulart Reis e outros, autores de trabalhos históricos de qualidade. Entrementes, é de justiça destacar nesse processo a figura de José Reis, quem veiculou na grande imprensa a import ncia da história da ci ncia, ao mesmo tempo que destacava, com simpatia, as atividades do pequeno grupo da USP. Este conseguiu dar mais um salto qualitativo, graças ao aux lio prestado por uma área inesperada - a da pol tica cient fica e tecnológica. Nos anos 70 e 80, alguns pol ticos e administradores de C\&T influentes, como José Pelúcio Ferreira e Lynaldo Cavalcanti de Albuquerque, consideravam a história da C\&T um instrumento importante para as suas aç es. E começaram a apoiar essa disciplina. Isso tornou poss vel, em 1979, a participaç o do grupo do Departamento de História/USP no Projeto Bra/76/022, intitulado Fortalecimento das Instituiç es de Ensino e Pesquisa Relacionadas Com Estudos de Pol tica Cient fica e Tecnol gica, dentro do Programa das Naç es Unidas Para o Desenvolvimento (PNUD), com o apoio do CNPq e da UNESCO.

Nessa nova etapa, com o nome de Núcleo de História da Ci ncia e da Tecnologia, o agrupamento da USP desenvolveu numerosos projetos de envergadura, obtendo bons resultados. Além do apoio decidido do $\mathrm{CNPq}$, contou com o aux lio de outras fontes de financiamento como CAPES, FAPESP, Secretária de Indústria, Comércio, Ci ncia e Tecnologia e Secretaria de Economia e Planejamento, ambas do Estado de $\mathrm{S}$ o Paulo. Promoveu e participou, do mesmo modo, congressos, simpósios, seminários, confer ncias e workshops, muitos dos quais alcançaram repercuss es significativas nos meios acad micos. Contou com a participaç o de numerosos docentes consagrados da USP, tais como os historiadores Fernando 
Novais, Arnaldo Contier e Carlos Guilherme Mota, os f sicos Mário Schenberg e Alberto Lu s da Rocha Barros, o engenheiro Milton Vargas, os sociólogos Oracy Nogueira, José Jeremias de Oliveira Filho e Gabriel Cohn, os arquitetos Júlio R. Katinsky e Ruy Gama, e outros, além de pesquisadores gabaritados de outras instituiç es, a saber: Oswaldo Fidalgo (Instituto de Bot nica da Secretaria de Agricultura do Estado de S o Paulo), José Ribeiro do Valle (Escola Paulista de Medicina, atual UNIFESP), Tamás Szmrecsányi e Ubiratan D’Ambrósio (UNICAMP) e Ronaldo Rogério de Freitas Mour o (Museu de Astronomia e Ci ncias Afins, MAST, Rio de Janeiro). Nesse processo, formou e estimulou a formaç o de jovens especialistas em história da ci ncia e da tecnologia.

Embora fecundo, esse estágio caracterizado pelo Núcleo de História da Ci ncia e da Tecnologia apresentava um sen o. Por ser um grupamento informal e mesmo virtual dentro da estrutura administrativa da USP, ele n o fornecia perspectiva profissional para jovens pesquisadores e pós-graduandos. Muitos deles, a despeito de terem realizados trabalhos, dissertaç es de mestrado e teses de doutorado de valor, acabavam migrando para outros dom nios em virtude da necessidade de sobreviv ncia. A idéia do Centro Interunidade surgiu para contornar essa situaç o. Seria uma maneira de colocar formalmente o grupo dentro da estrutura burocrática da universidade e um passo a mais para a criaç o de um departamento ou instituto especializado na área. Com esse propósito, S. Mathias e S. Motoyama realizaram gest es no sentido de concretizar o CHC, com o apoio inestimável do ent o Secretário de Economia e Planejamento do Estado de S o Paulo, Frederico Mazzuchelli. O reitor na ocasi o, José Goldemberg, acolheu a proposta, com simpatia e decis o e o Centro tornou-se em realidade.

De lá para cá, já se passaram 20 anos. O CHC, a par de dar continuidade as aç es que vem desenvolvendo, enfrenta novos e intrigantes desafios. Uma das atividades mais relevantes, apesar do pouco retorno pol tico, que vem efetuando há um bom tempo é a da preservaç o da memória cient fica e tecnológica, sobretudo do pa s. Est o sob a sua guarda dois importantes arquivos: Almirante Álvaro Alberto e Forman. Eles dizem respeito s quest es relativas a energia nuclear e a pol tica cient fica e tecnológica, assuntos inegavelmente de grande significado para a sociedade brasileira. Possui, também, parte da documentaç o da história da antiga Secretaria de Indústria, Comércio, Ci ncia e Tecnologia do Es- 
tado de S o Paulo. Faz parte, igualmente, do seu acervo, mais de duas centenas de depoimentos e entrevistas de cientistas, engenheiros e tecnólogos brasileiros. O desafio imediato é como manter em ordem e sem danificar essa documentaç o preciosa, tarefa nada fácil. Outro desafio, assaz relevante, converge na direç o da preservaç o da memória da própria USP, relegada até agora a segundo plano. A maior universidade do pa s, din mica e atuante em outros campos, parece comportar-se de forma muito t mida quando se trata da sua história. Em conseq ncia, já se perdeu muita documentaç o preciosa e informaç es históricas de alto valor. Está na hora de reverter esse quadro.

Outro aspecto essencial das atividades do $\mathrm{CHC}$ centra-se na quest o da formaç o de jovens profissionais da área. O Departamento de História da FFLCH v m prestando uma colaboraç o inestimável para esse objetivo, permitindo a elaboraç o de teses e dissertaç es especializadas em história da C\&T. Contudo, em funç o da magnitude da demanda e da interdisciplinaridade da matéria, as dificuldades s o cada vez maiores. Nesse aspecto, parece ter chegado o momento de estabelecer um curso de pós-graduaç o estrito senso de história da ci ncia e da tecnologia. Claramente, o lugar natural para tal curso é o Centro. Outra caracter stica deste, mesmo quando ainda era Núcleo de História da Ci ncia e da Tecnologia, tendo sido realizar pesquisas históricas sobre as atividades cient ficas e tecnológicas do pa s. A despeito de os resultados obtidos nessa seara serem ótimos, ainda falta muito para a compreens o do processo histórico em curso no dom nio da C\&T. É necessário implantar uma rede de pesquisadores espalhada em todo território brasileiro para alcançar a finalidade colimada. Outrossim, o mundo torna-se cada vez mais globalizado. A competiç o acirrada da resultante, só poderá ser vencida, se tivermos o dom nio e o controle de dados e informaç es, sobretudo, cient ficas e tecnológicas. Todavia, para a sua maior efici ncia, n o é suficiente somente os do presente. É preciso possuir séries históricas capazes de delinear o processo em marcha. Ou seja, deve-se recorrer história da C\&T. Destarte, o CHC tem de funcionar, também, como um instituto de informaç o e de pol tica cient fica e tecnológica - um desafio imenso.

Nesses tempos dif ceis e incertos de planetarizaç o, cheios de desafios para o CHC, a Revista khronos chega em boa hora. Como órg o oficial do Centro, ela deverá veicular os resultados dos seus trabalhos, seja das suas pesquisas, seja dos seus eventos e realizaç es. Todavia, mais do que isso, pretende 
ser um lugar privilegiado para a difus o e discuss o em alto $\mathrm{n}$ vel de quest es candentes sobre história da ci ncia, da história da técnica e tecnologia, da filosofia da ci ncia, da filosofia da tecnologia, da metodologia da ci ncia, da epistemologia, da sociologia da ci ncia e da pol tica cient fica e tecnológica, ao lado de assuntos correlatos. Acreditamos que ela venha a se constituir em instrumento importante para o $\mathrm{CHC}$ atuar, ainda que de modo limitado, para a melhoria da sociedade brasileira e do contexto internacional. Que Khronos cumpra esse destino, s o os nossos votos.

\section{Nota}

\section{* Diretor do CHC/USP}

